\title{
Trabalho, moradia e chefia familiar: o caso do processo de expansão portuária no Bairro Getúlio Vargas - Rio Grande (RS)
}

\author{
Work, Housing and Family Leadership: the case of the port expansion \\ process in Getúlio Vargas district - Rio Grande (RS)
}

\author{
Andressa Cristiane Colvara Almeida \\ Universidade Federal do Rio Grande \\ andressacolvara@yahoo.com.br \\ Susana Maria Veleda da Silva \\ Universidade Federal do Rio Grande \\ susanasilva@furg.br
}

\section{Resumo}

A partir de 2007, o processo de reorganização do Porto do Rio Grande-RS dá continuidade à ampliação de suas atividades em direção a localidades contíguas ou próximas às áreas portuárias. As áreas foram ocupadas por parcelas da população de baixa renda em diferentes momentos do crescimento do município. As possíveis remoções poderão acarretar modificações na rotina familiar e no trabalho, pois grande parte dos moradores(as) trabalha em locais próximos e depende da localidade onde moram para manter-se no emprego. O recorte espacial limita-se à área de ampliação portuária situada no bairro Getúlio Vargas (BGV). O objetivo principal é compreender a relação entre trabalho e moradia nas áreas sujeitas a remoção, através da articulação entre as alterações nos arranjos familiares associadas às transformações do papel das mulheres na família e no trabalho.

Palavras-chave: trabalho; moradia; chefia familiar; gênero.

\begin{abstract}
Since 2007, the reorganization of the Port of Rio Grande (RS - Brazil) proceeds to the extension of its activities towards localities that are contiguous or near the port areas. These areas have been occupied by portions of the low-income population at different times in the city's growth. The possible relocation may cause changes in the family and work routines, since a great part of the inhabitants work nearby and depend on the locality where they live to keep their jobs. The spatial scope of the study is limited to the extended port area situated in Getúlio Vargas district (BGV). The main objective is to understand the relation between work and housing in the areas from where citizens might be removed, through the articulation between the alterations in the familiar arrangements that are associated to transformations in women's role in the family and in the work place.
\end{abstract}

Keywords: work; housing; family leadership; gender. 
A partir de 2007, o processo de reorganização do Porto do Rio Grande-RS dá continuidade à ampliação de suas atividades em direção à Vila Mangueira, à Barra Nova, à Barra Velha, ao bairro Santa Tereza e ao bairro Getúlio Vargas. Todas estas localidades são contíguas ou próximas às áreas portuárias e foram ocupadas por parcelas da população de baixa renda em diferentes momentos do crescimento do município. População que ainda hoje enfrenta a possibilidade de remoção de suas casas, o que poderá acarretar modificações na rotina familiar, principalmente no que se refere ao trabalho. Isso porque grande parte dos moradores(as) trabalha em locais próximos a estas áreas e depende da localidade onde moram para manter-se no emprego.

A pesquisa tem como objetivo principal compreender a relação entre trabalho e moradia nas áreas sujeitas a remoção, através da articulação entre as alterações nos arranjos familiares associadas às transformações do papel das mulheres na família e no trabalho. $\mathrm{O}$ recorte espacial aqui apresentado limita-se à área de ampliação portuária situada no bairro Getúlio Vargas (BGV).

Esta área foi definida a partir de negociações entre os agentes envolvidos: a Superintendência do Porto do Rio Grande (SUPRG), os moradores(as) representados pela Associação dos Moradores e Amigos do Bairro Getúlio Vargas (AMABGV) e o Movimento Nacional de Luta por Moradia (MNLM). Tais agentes indicaram que a delimitação da área do bairro Getúlio Vargas atingida pela expansão portuária compreende uma faixa de 15 metros de largura paralela ao muro do parque automotivo do Porto Novo onde será construída uma avenida ligando a Rua Dom Pedro II até a BR-392 (MARTINS, 2008). A faixa abrange uma área densamente povoada, com muitas residências e ruas desalinhadas e estreitas, abertas conforme foi ocorrendo a ocupação (Figura 1).

Em 2000, a população total do bairro Getúlio Vargas era de 10.974, com 5.264 homens e 5.710 mulheres (IBGE - CENSO DEMOGRÁFICO, 2000). O Censo de 2010 contabilizou uma população total de 10.367 pessoas, sendo $53 \%$ do sexo feminino. Em 2007, pesquisa socioeconômica realizada pelo Núcleo de Análises Urbanas (NAU-FURG) contabilizou 1.245 moradores(as) na área de remoção, destes, 597 homens e 648 mulheres (MARTINS, 2008). Tanto no BGV como na área de remoção, as mulheres representam mais da metade da população (52\%). Esta participação de mulheres na população total é expressiva quando comparada com a nacional (51,04\%), a estadual $(51,33 \%)$ e a municipal $(51,84 \%)$ (IBGE - CENSO DEMOGRÁFICO, 2010).

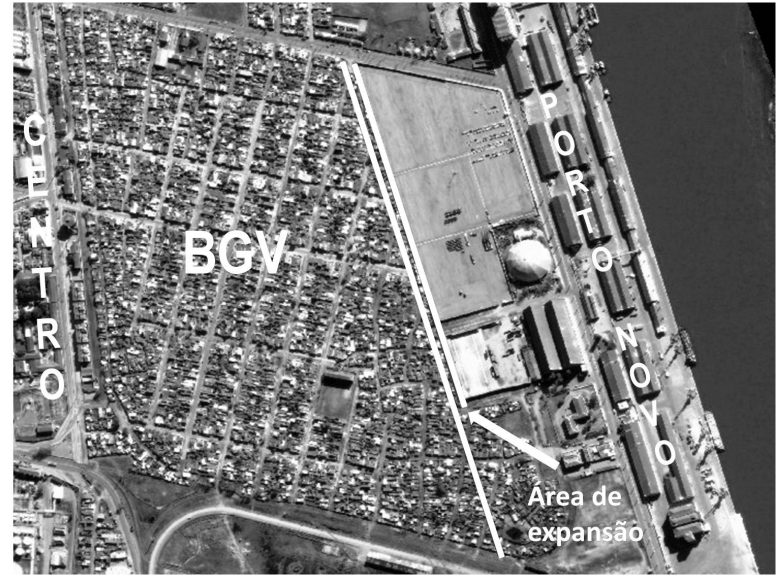

Figura 1: Área do bairro Getulio Vargas atingida pela expansão portuária. Fonte: Relatório BGV/ NAU, 2008. Adaptado por Andressa C. Colvara Almeida

A pesquisa do NAU foi respondida por 372 moradores(as) que se identificaram como chefes de família, 207 homens e 165 mulheres. Este artigo apresenta os resultados obtidos a partir do perfil destes moradores(as) responsáveis pelos domicílios, com ou sem filhos e com ou sem companheiro.

Em 1996 os dados do Instituto Brasileiro de Geografia e Estatística (IBGE) apontavam que as mulheres eram responsáveis por $18,11 \%$ das famílias moradoras no BGV. Na área de remoção, $44,35 \%$ das famílias possuem como responsável uma mulher, número significativo quando observamos que em 2000 , o Brasil possuía $24,9 \%$ de domicílios chefiados por mulheres (IBGE, Censo demográfico, 2000). Estudo do Instituto de Pesquisa Econômica Aplicada (IPEA) realizado com base nos dados da Pesquisa Nacional por Amostra de Domicílio (PNAD) indicou para o País um aumento de $27,34 \%$ em 2001 para $35,17 \%$ em 2009.

Estudos apontam a necessidade de (des)construir o "objeto mulher chefe de família" (MACÊDO, 2001, p. 78) dado seu perfil diverso. Esta diversidade impõe caminhos metodológicos que evidenciam a importância da realidade empírica para explicar, a luz das categorias de análise, a própria realidade. Portanto, justificamos que o presente artigo tem como questão de partida investigar comparativamente qual é o perfil sociodemográfico dos chefes de família e demonstrar qual é a relação entre a ocupação destes moradores(as) (as) e a área de moradia.

Para responder a essas questões elaboramos um perfil demográfico e socioeconômico comparativo entre os homens e as mulheres chefes de família da área em estudo tendo como constructos intelectuais a categoria gênero e os conceitos de divisão sexual do trabalho e chefes de família. A caracterização 
quantitativa dos moradores(as) da área foi realizada a partir do banco de dados do Núcleo de Análises Urbanas - NAU (MARTINS, 2008). Os indicadores sociais por sexo — escolaridade, número de filhos, situação familiar, renda, ocupação e situação de trabalho - , desenham o grupo de moradores(as) e indicam diferenças socioeconômicas entre os homens e as mulheres. Realizamos entrevista com a secretária da associação dos moradores(as) do BGV que é também uma chefe de família moradora do bairro.

$\mathrm{O}$ artigo está estruturado em três partes. $\mathrm{Na}$ primeira, tratamos de esclarecer os conceitos e as categorias de análise e interpretação e, na segunda, caracterizamos os moradores(as) qualificando os números. Ao final, tecemos algumas considerações.

\section{Discutindo conceitos}

Estabelecer a condição de chefe de família ou de domicílio atende a duas demandas, a primeira, relativa a coleta de dados empíricos quantitativos e, a segunda, relativa a questões teórico-metodológicas, fundamentadas na categoria gênero. Para a primeira demanda a definição do conceito de chefe de família e/ou domicílio está explicitada nas notas metodológicas do Instituto Brasileiro de Geografia e Estatística (IBGE). Na segunda, consideramos o objeto de estudo a partir das relações de gênero, assim, o conceito é matizado pela sua condição concreta. Estamos de acordo com Saffioti (2000, p.71) quando argumenta que "só as e os estudiosos do tema têm o privilégio de abandonar os preconceitos necessários à análise da condição feminina. Obviamente, não bastam os conceitos. Dados também são necessários".

Para elaborar levantamentos demográficos é necessário o conhecimento das relações entre os moradores(as) no domicílio, para tanto é preciso que se identifique o chefe ou responsável ou a pessoa de referência e, depois, as pessoas restantes, de acordo com sua relação com o chefe ou responsável ou a pessoa de referência. Esta pessoa é aquela definida pelos moradores(as) como tal. No Brasil os censos e pesquisas domiciliares utilizaram, durante muitos anos, a denominação 'chefe do domicílio' e 'chefe da família'. O termo chefe do domicílio ou chefe da família sempre esteve associado à autoridade e responsabilidade pelos negócios da família e, na maioria dos casos, a mais importante fonte de sustento. Estas denominações, contextualizadas no seu tempo, constavam nos Censos de 1872 e 1890. Os dados mostraram, ao longo dos anos, a predominância de pessoas do sexo masculino, nessa escolha do 'chefe de família' (IBGE, 2011). Essa situação começou a se modificar somente a partir dos anos 1970 e se intensifica nas décadas seguintes, pois, paralelo ao aumento da participação das mulheres na população economicamente ativa, aumenta o papel dos movimentos feministas, introduzindo novos paradigmas para o comportamento das mulheres e das famílias. A participação das mulheres no mundo do trabalho remunerado passa a ser considerado como uma condição necessária para a emancipação, e não apenas como meio de sobrevivência econômica.

Os Censos Demográficos de 1960 e 1970 e as PNADs de 1981-1990 quantificaram a 'condição no domicílio' considerando a relação de convivência entre cada morador e o chefe do domicílio. Nesta relação, o chefe de família era a pessoa responsável pela família. As PNADs de 1992-1999 substituem o termo 'chefe de família' para a 'pessoa de referência'. Para a elaboração do Censo 2000 os pesquisadores do IBGE identificaram que muitas pessoas não entendiam o significado da palavra 'referência' e optaram pelo termo 'pessoa responsável pelo domicílio', aquela reconhecida como tal pelos demais moradores(as), seja homem ou mulher, e seria a primeira pessoa do domicílio a ser registrada no questionário. O Censo 2000 identificou que 24,9\% dos domicílios brasileiros tinham como 'pessoa responsável' uma mulher.

O Censo 2010 trabalhou com a concepção de 'arranjos familiares'. Os moradores(as) deveriam indicar um responsável pela residência para definir as outras relações, mas esta pessoa pode compartilhar sua responsabilidade. Nesta nova tipologia cabem diversos arranjos familiares e é possível identificar a responsabilidade das mulheres sozinhas ou com companheiros e as corresponsabilidades.

As mudanças nas definições metodológicas, para fins de coleta de dados, de condição no domicilio ou na família apontam para uma preocupação em retirar a palavra chefe do vocabulário metodológico e substituir por pessoa de referência ou responsável. A condição de chefe está marcada por uma estrutura familiar patriarcal e não atende as demandas impostas pelos novos arranjos familiares.

Para os anos de 1990, Goldani (1994) demonstrou que embora as famílias brasileiras ainda morassem em domicílios organizados por laços de parentesco, o período já indicava novos arranjos domésticos, como pessoas vivendo sozinhas ou grupos não familiares compartilhando a mesma unidade residencial. Os arranjos domésticos organizados por famílias diminuem de tamanho por dois motivos principais: a queda da taxa de fecundidade e o aumento de separações. Este último, juntamente com o aumento de mães solteiras e de viúvas é responsável pelos arranjos monoparentais, compostos principalmente por mães com filhos. A estrutura etária se modifica com a queda 
da natalidade e da mortalidade e a expectativa de vida aumenta. As mulheres vivem mais e aumenta o número de unidades domésticas que tem mulheres como principais provedoras da família. A família diminui de tamanho, porém aumenta o número de membros que trabalham (GOLDANI, 1994, p. 14).

Diversos estudos sobre o tema apontam para a dificuldade metodológica e teórica do uso do termo 'chefe/chefia de família' para identificar as mulheres responsáveis pela família. Termo marcadamente hierárquico e androcêntrico, indicando um imbróglio conceitual. Nos limites deste artigo utilizamos o termo 'chefes de família' para os entrevistados responsáveis pelo domicílio, considerando que tem sido uma nomenclatura aceita popular e academicamente. Porém, como os autores que trabalham a temática, matizamos o conceito a partir das relações de gênero considerando a divisão sexual do trabalho. Esta divisão, a partir da concepção patriarcal, impõe papéis ou funções sociais aos homens, considerados — os provedores - e, portanto, os 'chefes' que representam a autoridade na família. As mulheres são as administradoras domésticas (MACÊDO, 2001), neste caso, as 'chefes de família' subvertem esta divisão e/ou acumulam funções.

Butler (2008) afirma que gênero é um modo contemporâneo de organizar normas passadas e futuras, um modo de nos situarmos e através dessas normas, um estilo ativo de viver nosso corpo no mundo. Portanto se os papéis atribuídos aos sexos são normativos e apreendidos, podem ser transgredidos e modificados. Assim justificamos a importância de considerar a perspectiva feminista nos estudos geográficos, particularmente nos temas populacionais, pois ainda corremos o risco de uma regressão e uma desvalorização de conquistas socioespaciais oriundas das lutas feministas. Segundo Lopes (2006, p.407):

No momento atual, esta é uma necessidade imperativa. Isso porque as mulheres da geração de hoje já não se dão conta do quê significam as conquistas das gerações anteriores, principalmente porque para muitas pessoas a luta feminista é vista como algo já superado (e 'superados' seriam seus defensores).

Como vimos o conceito de mulheres chefes de família está eivado de uma concepção de família patriarcal. Neste sentido a chefia feminina como negação da chefia masculina, transgride a norma. Problematizar o conceito requer pensá-lo como produto e produção das relações de gênero. A categoria gênero ilumina a questão, pois faz referência a todas as diferenças entre homens e mulheres que foram construídas social e culturalmente. As diferenças construídas produzem e reproduzem as desigualdades sociais. O acesso ao trabalho remunerado afirma e reproduz a desigualdade entre os sexos, demonstrada na divisão sexual do trabalho, que possui origem no âmbito familiar e se reflete nas ocupações remuneradas extra domiciliares. Por isso, exalta-se a importância dos estudos das relações entre trabalho e gênero, como assegura Montali (2000, p. 63):

A divisão sexual do trabalho opera tanto na família como no mercado de trabalho através de conteúdos históricos e culturais. Dessa maneira, são os conceitos da divisão sexual do trabalho e das relações de gênero que possibilitam explicar os modos diferenciados de inserção de homens e mulheres no sistema produtivo, bem como as formas de gestão da força de trabalho também diferenciadas por sexo, que nos auxiliam a entender os efeitos diferenciados da reorganização das atividades econômicas sobre o emprego masculino e o feminino.

Demo (2005), estudando as mulheres chefes de família no entorno de Brasília, verifica que a inserção no mercado é fundamental para que as pessoas possam manter-se com autonomia, sem depender de auxílio dos outros, no caso feminino, na dependência masculina e confirma que a chefia feminina se dá majoritariamente no espaço urbano. Esse mesmo aspecto é perceptível na fala da chefe de família entrevistada, que também é secretária da associação do bairro:

(...) eu acho que trabalho é uma questão de dignidade. Hoje tu ocupar um espaço no mercado de trabalho, tem haver com a tua dignidade, com a tua autoestima, com uma série de coisas. Claro que há diversos tipos (...) desse prazer que te dá. Tu sabe que tem mulheres que às vezes estão esgotadas, estão com problemas, uma série de coisas, elas nem tão sabendo que tão com tudo isso e o trabalho passa a ser maçante (...).Ela está trabalhando pela dignidade, pela sua autoestima pelo trabalho e ela não tem vergonha de trabalhar(...). Então o quê que é o prazer? A questão de autonomia (secretária da $A M A B G V, 2011$ )

Questionamos um aspecto por vezes negligenciado: conhecer como as mulheres estão 
inseridas no mercado de trabalho considerando seu local de moradia.

O BGV é o recorte espacial desta pesquisa e o estudo sobre seus moradores(as) através do acesso ao mercado de trabalho e a posição ocupada dentro da família possibilita inferências sobre as outras áreas de expansão portuária.

\section{Chefias familiares na área de expansão do BGV}

O BGV iniciou a construção de habitações no início do século $\mathrm{XX}$, com os investimentos na área portuária. A partir de uma estratégia geográficoeconômica instalam-se indústrias que demandaram trabalhadores. A metade sul do estado passava por uma queda das atividades pecuaristas provocando uma migração para área. Lopes (2008) afirma que estes desapropriados da atividade laboral pecuarista, passaram a formar uma vila operária não regulamentada pelo Estado, segundo o autor,

A construção social do BGV apresenta algumas peculiaridades, tendo como referência a localização da área escolhida para a produção do espaço social pelos trabalhadores, destacam-se as seguintes: a primeira relaciona-se as relações sociais e estratégicas de resistência e de sobrevivência, proporcionadas, pela proximidade de moradia aos locais de emprego e pelos processos de autoconstrução de moradias. (LOPES, 2008, p. 30).

Ainda hoje identificamos uma ligação entre o local de moradia e a atividade laboral no bairro. Indagamos se existem as mesmas possibilidades de inserção no mercado de trabalho para homens e mulheres chefes de família. A seguir caracterizamos os moradores(as) da área em tela demonstrando esta relação e apresentamos os dados quantitativos através de gráficos com os valores absolutos e os percentuais. O banco de dados utilizado foi formado a partir de questionários que se apresentam divididos nas seguintes categorias: dados pessoais dos entrevistados (chefes de família), dados sobre os familiares, sobre trabalho e sobre renda da família, sobre a infraestrutura do domicílio e infraestrutura básica do BGV.

A fim de caracterizar os chefes de família, selecionamos os seguintes dados: faixa etária; número de filhos residentes; presença ou não de companheiro; renda familiar e situação, ocupação e local de trabalho. As ocupações foram classificadas de acordo com a
PNAD (2005).

Os chefes de família da área de expansão portuária do BGV são jovens adultos. A maioria concentra-se na faixa entre 26 e 35 anos de idade, porém é expressiva a faixa entre 15 e 25 anos. O bairro é marcado por alguns incidentes de violência, que acaba por atingir principalmente essa população mais jovem, que, de modo geral, não apresenta grandes expectativas, como afirma a secretária, quando comenta: “(...) o jovem, eu acho que o jovem é a tua inspiração, é eles que não tem mais nada pra fazer. Tu vê hoje um jovem na esquina (...). Nós temos uma rua principal(...)altos tiroteios" (secretária da AMAGBV, 2011).

A maior parte pertence a população em idade ativa, portanto, está apta ao mercado de trabalho (ver Gráficos 1 e 2). Segundo a entrevistada, apesar de cursos de capacitação oferecidos, surgidos como consequência dos recentes investimentos na cidade, poucos são os que procuram

\section{(...) pra eles tá tudo bom, eles não enxergam a dificuldade nem conseguem enxergar o amanhã, que Rio Grande vai se tornar uma cidade com muita população, que, de repente, esse mercado que tem aí as oportunidades como o PROJOVEM, o PROMINP(...) tem esse espaço, é só eles irem pra uma fila se qualificar (secretária da $A M A B G V, 2011)$.}

A idade máxima para as mulheres é de 84 anos e para os homens, 72. Corroborando os dados demográficos do IBGE que indicavam em 2000, uma expectativa de vida de 64,8 anos para os homens e 72,6 para as mulheres no Brasil, destacamos que a maioria das pessoas responsáveis pelo domicílio com mais de 66 anos são do sexo feminino. Indicando que mais mulheres do que homens auxiliam no sustento da família através da renda de aposentadorias e de pensões (Gráficos 1 e 2).

As famílias que não possuem filhos residentes no domicílio estão representadas em $33 \%$ das chefias masculinas e $23 \%$ das chefias femininas; $61 \%$ das famílias chefiadas por mulheres convivem com um a três filhos enquanto que as chefiadas por homens o percentual é $51 \%$ (ver Gráficos 3 e 4). Esses dados demonstram maior incidência de filhos nas famílias chefiadas por mulheres, indicando que permanecem com a mãe nos casos de separação. 
Gráfico 1: Faixa etária das mulheres chefes de família na área de expansão do BGV, 2007.

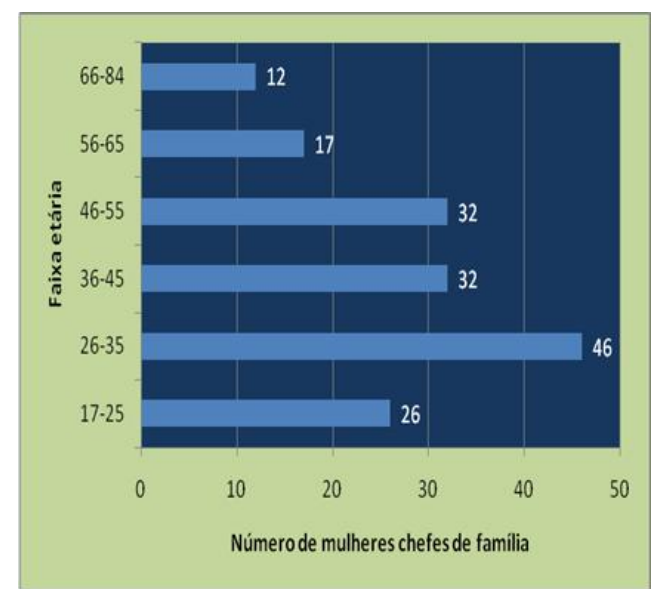

Fonte: MARTINS, 2008. Elaborado por Andressa Cristiane Colvara Almeida.

A maior presença de filhos nos domicílios de mulheres chefes de família imputa uma sobrecarga nos afazeres e nas responsabilidades domésticas oriundas da divisão sexual do trabalho, levando a uma maior exploração do trabalho feminino, através da dupla, tripla ou mesmo quádrupla jornada de trabalho. Mendes afirma que

Apesar delas terem assumido atribuições consideradas tradicionalmente masculinas, o mesmo não ocorre em relação aos homens, que na maioria das vezes não as substitui no âmbito do doméstico, e quando o faz é parcialmente, alegando que determinados serviços não podem e não devem ser feitos por homens. Sendo assim, a administração da casa e filhos continua ainda sob a responsabilidade da mulher, o que faz com que a sua carga de trabalho seja não só duplicada (...), mas quadruplicada, exercendo a um só tempo papéis distintos que requerem eles próprios suas atividades

Gráfico 3: Filhos residentes nos domicílios chefiados por mulheres na área de expansão do BGV, 2007.

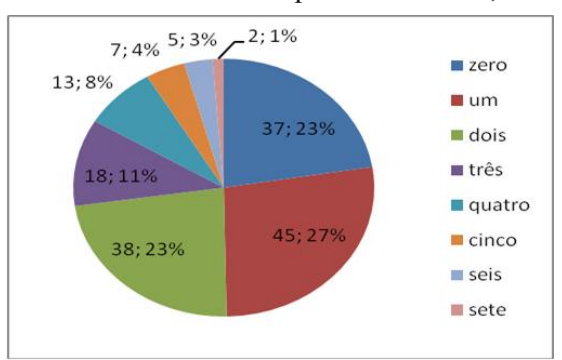

Fonte: MARTINS, 2008. Elaborado por Andressa Cristiane Colvara Almeida.
Gráfico 2: Faixa etária dos homens chefes de família na área de expansão do BGV, 2007.

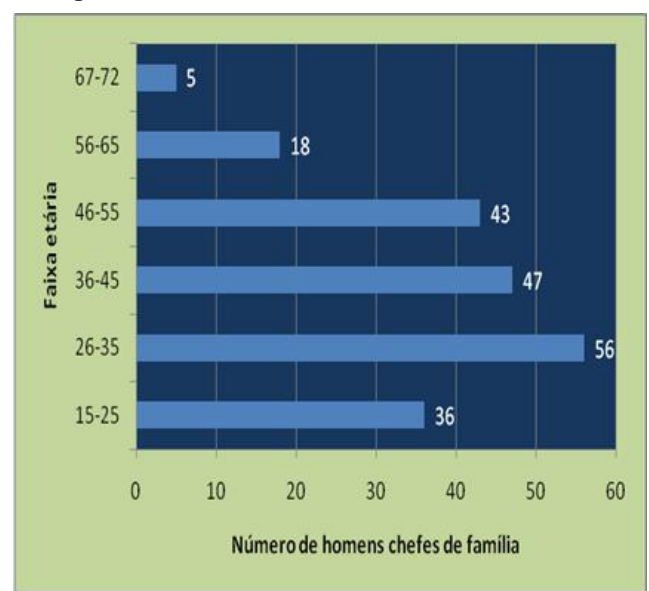

Fonte: MARTINS, 2008. Elaborado por Andressa Cristiane Colvara Almeida.

específicas, quais sejam, o de líder comunitária, trabalhadoras avulsas, dona de casa, mãe e esposa! (MENDES, 2002, p. 8).

Corroborando com esse pensamento, a secretária da associação, também exerce múltiplas funções: chefe de família, estudante de Administração de Empresas em uma faculdade privada e tem um emprego formal de assessora na Secretaria Municipal de Cidadania e Assistência Social (SMCAS). Além disso, é radialista, guia de turismo e atua politicamente desde seus 18 anos assessorando alguns vereadores. A secretária dá destaque à ocupação formal quando diz: “é o meu básico, é da onde eu pago o meu INSS, é obrigado a ter né. E por fora é onde tu consegues, porque só com esse dinheiro eu não faria nada. Não daria para nada.". Também deixa clara sua satisfação em trabalhar fora da esfera doméstica, que considera sua obrigação: “(...) sempre fui mais de trabalhar, eu gosto mesmo é de trabalhar, embora a gente tenha a obrigação de fazer as coisas dentro de casa."

Gráfico 4: filhos residentes nos domicílios chefiados por homens na área de expansão do BGV, 2007.

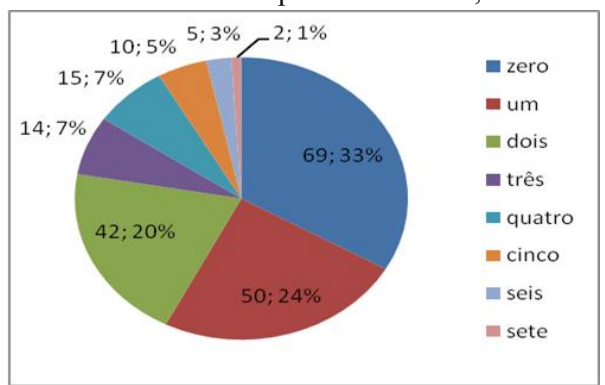

Fonte: MARTINS, 2008. Elaborado por Andressa Cristiane Colvara Almeida.

Andressa Cristiane Colvara Almeida e Susana Maria Veleda da Silva 
Os dados analisados demonstraram a relação entre a responsabilidade familiar feminina (chefia) e a ausência de um companheiro. Inferimos que somente $28 \%$ das mulheres que vivem com um companheiro, declararam-se como responsáveis por sua família, para os homens o percentual foi de $74 \%$. Essa relação demonstra o quanto a chefia masculina ainda é considerada como a 'correta' para o arranjo familiar, já que somente na ausência de um cônjuge/companheiro masculino as mulheres colocaram-se na responsabilidade familiar.

Gráfico 5: Presença de companheiro nos domicílios chefiados por mulheres na área de expansão do BGV, 2007.

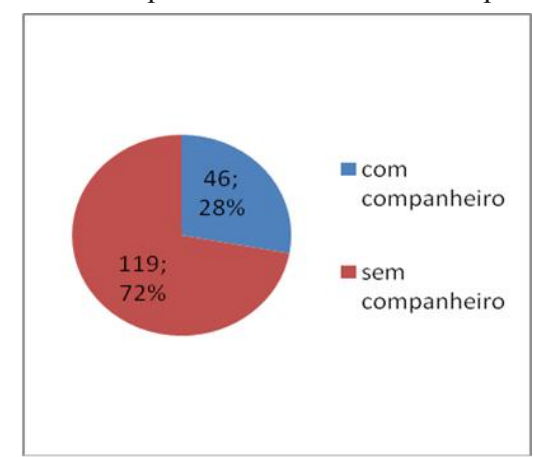

Fonte: MARTINS, 2008. Elaborado por Andressa Cristiane Colvara Almeida.

Mais da metade dos chefes de família apresenta baixa escolaridade, $64 \%$ das mulheres e $65 \%$ dos homens possuem o ensino fundamental incompleto. Destacamos que o maior percentual de analfabetos está entre as mulheres e o maior percentual de pessoas com o ensino fundamental e médio completo é dos homens. A maior diferença está entre os que possuem o médio incompleto, estando elas com $10 \%$ e eles com $6 \%$ (ver Gráficos 7 e 8).

Gráfico 6: Presença de companheira nos domicílios chefiados por homens na área de expansão do BGV, 2007.

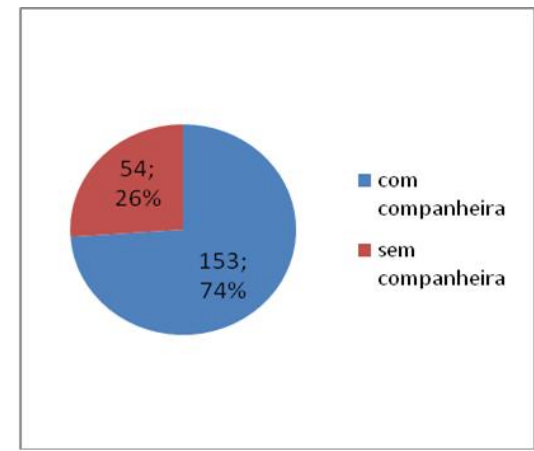

Fonte: MARTINS, 2008. Elaborado por Andressa Cristiane Colvara Almeida.
Gráfico 7: escolaridade das mulheres chefes de família na área de expansão do BGV, 2007.

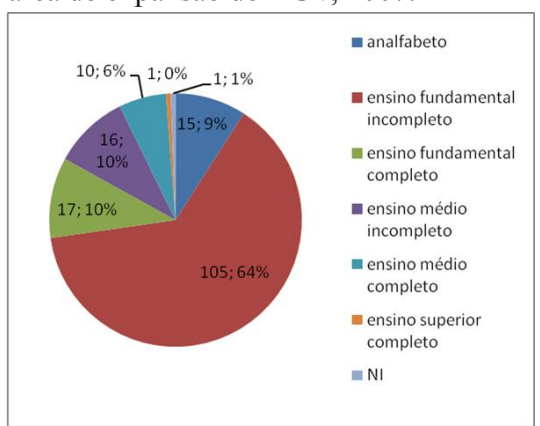

Fonte: MARTINS, 2008. Elaborado por Andressa Cristiane Colvara Almeida.

Gráfico 8: escolaridade dos homens chefes de família na área de expansão do BGV, 2007.

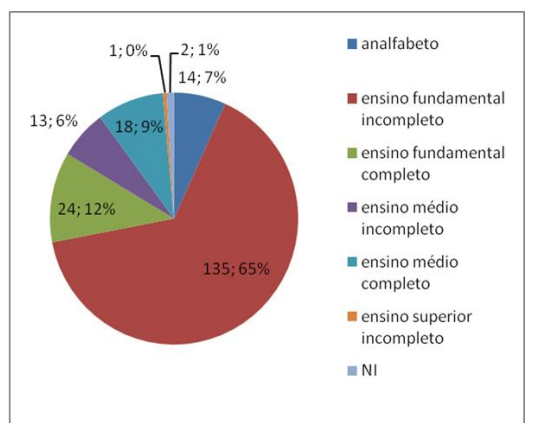

Fonte: MARTINS, 2008. Elaborado por Andressa Cristiane Colvara Almeida.

Os dados mostram que não há grande discrepância entre a escolaridade dos chefes de família do sexo masculino e feminino, uma diferença que poderia tornar desigual o acesso ao mercado de trabalho e, consequentemente, a renda familiar. Contudo, os dados a seguir demonstram a desigualdade das rendas familiares de acordo com o sexo da chefia (ver Gráficos 9 e 10).

Gráfico 9: renda familiar mensal das famílias chefiadas por mulheres na área de expansão do BGV, 2007.

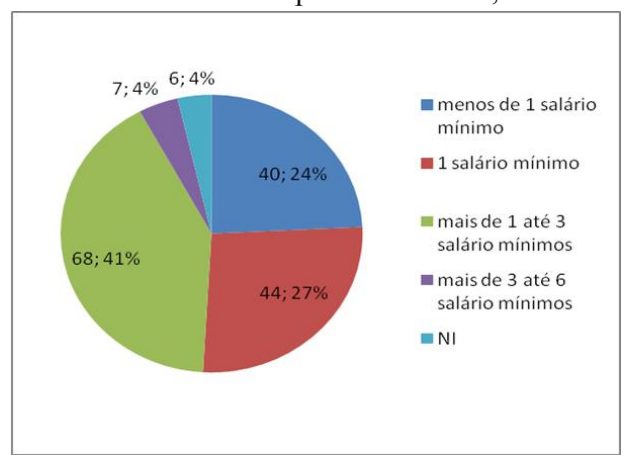

Fonte: MARTINS, 2008. Elaborado por Andressa Cristiane Colvara Almeida. 
Gráfico 10: renda familiar mensal das famílias chefiadas por homens na área de expansão do BGV, 2007.

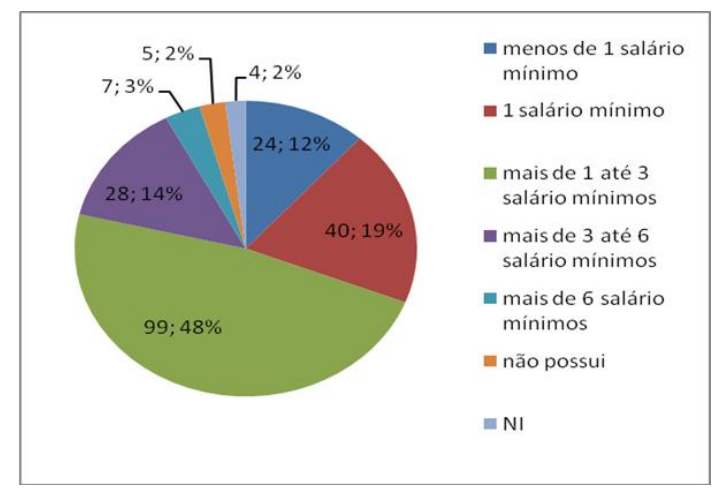

Fonte: MARTINS, 2008. Elaborado por Andressa Cristiane Colvara Almeida.

A faixa de renda predominante das famílias da área é de mais de um a três salários mínimos. Porém há diferenças que precisam ser salientadas. A primeira trata-se da renda familiar de no máximo um salário mínimo que, no caso masculino (incluindo os $2 \%$ que declararam não possuírem renda), fica em 33\%. Já no caso feminino, esse percentual é bem maior, ficando com $51 \%$. A segunda é o aparecimento da faixa de mais de seis salários mínimos nas famílias de chefia masculina e, para as chefias femininas, é de no máximo seis salários mínimos. A renda familiar de mais de três a seis salários mínimos é de 14\% nas famílias chefiadas por homens e de $4 \%$ nas chefiadas por mulheres. Os dados demonstram que as famílias da área chefiadas por mulheres são as mais pobres, uma situação já identificada para o Brasil em 1989 por Goldani (1994).

Gráfico 11: situação de trabalho das mulheres chefes de família na área de expansão do BGV, 2007.

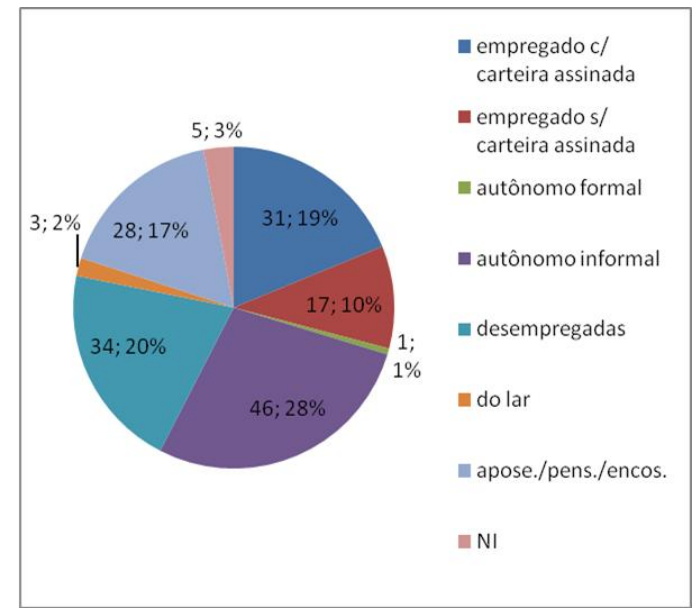

Fonte: MARTINS, 2008. Elaborado por Andressa

Cristiane Colvara Almeida.
Gráfico 12: situação de trabalho dos homens chefes de família na área de expansão do BGV, 2007.

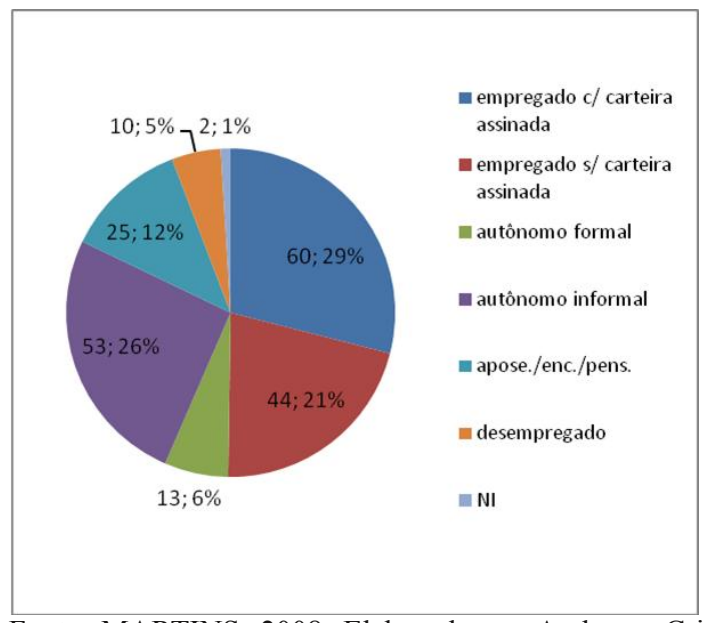

Fonte: MARTINS, 2008. Elaborado por Andressa Cristiane Colvara Almeida.

A situação de trabalho de homens e mulheres da área em questão é bem diferente no que tange a formalidade. Levando-se em conta somente os que têm uma atividade remunerada, os homens possuem formalidade em $42,94 \%$ e as mulheres $33,68 \%$, ou seja, o maior percentual de informalidade está nas ocupações das mulheres, 66,31\%. Essa realidade pôde ser percebida na renda inferior nas famílias onde a mulher é responsável pelo domicílio (ver Gráficos 9 e 10).

Além desse fator há o elevado percentual de desempregadas que é quatro vezes maior do que os desempregados. Também deve-se considerar que há um valor menor de mulheres com atividade remunerada - 58\%, enquanto que $82 \%$ dos homens exercem tal atividade. Muitas das mulheres não tem atividade remunerada pois enquadram-se nas categorias de aposentadas, pensionistas e do lar, semelhante ao estudo de Montali que demonstrou "o crescimento da importância dos rendimentos das chefes femininas não-ocupadas - provenientes de aposentadorias e pensões, bem como de trabalhos esporádicos - para provisão familiar" (2006, p. 241) na Região Metropolitana de São Paulo entre 1985 e 2003.

As atividades das mulheres chefes de família da área concentram-se nos serviços domésticos, tais como diaristas, empregadas domésticas e lavadeiras, destas, quatro também são aposentadas ou pensionistas sendo que três estão representadas entre as autônomas informais e uma como empregada com carteira assinada (ver Gráfico 11). Esses serviços em geral são feitos de forma autônoma e informal. Indicando a precariedade laboral das trabalhadoras da 
área, pois como afirma Hoffmann e Leone (2004, p. 36):

As ocupações menos valorizadas e tradicionalmente femininas do mercado de trabalho continuam se reproduzindo, implicando a persistência de nichos ocupacionais, como, por exemplo, o do emprego doméstico. O aumento do emprego doméstico aliado ao aumento do trabalho autônomo reflete maior proporção de mulheres na informalidade, desprotegidas de qualquer regulamentação que lhes garanta importantes direitos sociais, como carteira de trabalho assinada, licençamaternidade e acesso a creche, entre outros.

Essa questão também é reconhecida pela entrevistada:

\section{Hoje nós também temos mulheres, principalmente, que são as que mais estudam, ta cientificamente comprovado, que tem o segundo grau completo, mas que, daqui a pouco, pra sua sobrevivência, elas têm que trabalhar em qualquer coisa. Seja como empregada doméstica, seja como serviços gerais e pesados, como trabalhar na fábrica né. (secretária da $A M A B G V$, 2011)}

Destaca-se os $17 \%$ de mulheres que não exercem nenhuma ocupação (ver Gráfico 11), sendo que sua renda é proveniente exclusivamente de aposentadorias ou pensões. Contudo, salienta-se que, apesar das grandes dificuldades e desvantagens do trabalho feminino, percebemos que essa inserção no mercado de trabalho abre uma probabilidade de maior participação, dando-as possibilidade de 'empoderar- se' já que assumem uma posição frente às decisões domiciliares, sendo possível uma transformação no que tange seu papel na família e, consequentemente, na sociedade como um todo, como afirma Montali (2000, p. 61),

(...) colocam em discussão a questão de que a permanência e a mudança desse padrão de família culturalmente aceito passam pela ruptura ou não da possibilidade concreta de sua efetivação. Essa ruptura, por hipótese, tenderá a provocar uma nova divisão do trabalho na família, ou seja, a alterar a relação família trabalho, levando, a médio ou a longo prazo, a uma nova divisão sexual do trabalho que implicaria uma redefinição dos papéis masculino e feminino e alterações nas relações de hierarquia e poder.

É notável o empoderamento que se percebe na fala da secretária, que se vê no trabalho remunerado ou na associação:

(...) porque hoje a mulher (...) tem homem em dentro de casa e é elas q fazem tudo, é elas que engatinham pro homem conseguir, é elas que tem que ta implorando, aturando. Então, ás vezes, é melhor tu tá sozinha (...) e eu tenho uma coisa, eu digo:- $1^{o}$ sou eu, $2^{o}$ sou eu, $3^{\circ}$ sou eu. E a tua filha? Se eu não tiver bem comigo mesma, eu não trato bem a minha filha, eu não trato bem a mim mesma né, Porque tu fica anulada, Então eu acho que a gente tem que se libertar né. As minhas amigas: - ai, tu é muito...não, eu não sou, $1^{\circ}$ eu em tudo, se eu tiver bem eu trato tudo bem, tudo ótimo, não tenho medo de nada (...) eu acho que é a tua postura né. (...)com certeza, se tu deixar as pessoas te barram né. Se tu deixar, isso não é só eu, mulher negra, é com o espaço da mulher né, a mulher tem isto. Tu vai pra um setor onde que o homem acha que manda e não aceita que a mulher tenha mais saber, porque isso é o machismo, tu também vai passar por isso. (secretária da $A M A B G V$, 2011)

Ao investigar as ocupações dos entrevistados, considerando seu local de trabalho notamos que grande parte trabalha, principalmente, em três locais: no $\mathrm{BGV}$, na área portuária ou no centro da cidade, que é próximo ao bairro. Demonstrando a importância do local de moradia para o sustento das famílias da área.

A análise dos dados referentes às ocupações mostrou que grande parte das ocupações masculinas está ligada ao porto de Rio Grande, enquanto que limita-se a um caso a presença feminina na área portuária. É perceptível uma divisão sexual do trabalho pelas ocupações, pois às mulheres ficam concentrados os serviços que remetem ao trabalho reprodutivo ou ligados ao atendimento ao público, tais como: lavadeira, doméstica, balconista, vendedora, cozinheira, tarefeiras nas fábricas de peixe e ambulantes catadoras de material reciclável.

Os homens, em 18 casos, ocupam atividades na construção civil, como pedreiro, pintor, carpinteiro e eletricista. Nas fábricas de pescado, para os homens, 
há maior variedade de ocupações — dois balanceiros; quatro descarregadores de pescados; quatro tarefeiros e cinco nos serviços gerais -, do que nos casos femininos: dezenove tarefeiras e quatro nos serviços gerais.

A família com chefia feminina está em desvantagem socioeconômica, principalmente se levarmos em consideração que há uma exclusão espacial do trabalho feminino no porto, pois mesmo com a proximidade, ainda há a supressão historicamente construída do trabalho feminino em áreas portuárias. Nota-se que a secretária confirma essa segregação:

\section{fiz diferencial, entrei numa assembleia que não entra mulher , pra discutir coisas interessantes. Quando souberam que eu tava lá, - manda descer. Já to até aqui se fingindo de louca, entendeu? Então eu fiz o diferencial, eu sou a primeira mulher que teve numa assembleia (...) e mais ainda, nós não temos mulheres no porto, operacional. Que deveríamos ter, se nós somos uma referência, o segundo maior porto, por que nós não temos isto né? (secretária do AMABGV, 2011)}

Estas atividades proporcionam o maior número de empregos formais para os homens, pois 40 dos 73 entrevistados com trabalho formal eram trabalhadores da área portuária. Área que está recebendo investimentos estatais através do Programa de Aceleração do crescimento - PAC. Dada a situação das famílias consideramos que estes investimentos proporcionarão melhores condições às famílias com chefia masculina. As famílias chefiadas por mulheres não se beneficiariam, pois as mulheres exercem atividades informais que lhe são oferecidas no entorno das moradias, mantendo um padrão inferior às famílias chefiadas por homens.

\section{Algumas reflexões}

O termo chefe de família está marcado pela ideologia da família patriarcal, mas vem sendo problematizado teórica e metodologicamente. A partir da década de 1970, os movimentos feministas aliados a inserção maciça das mulheres no mundo do trabalho produzem transformações culturais que possibilitam novos arranjos familiares, com novos papéis das mulheres frente à família e um aumento de mulheres responsáveis por suas famílias como provedoras ou coprovedoras, com ou sem cônjuges.
A relação mulher chefe de família e trabalho remunerado torna-se uma questão importante tanto no que se refere às condições de subsistência das famílias como nas possíveis formas de autonomia que o acesso ao trabalho possibilita. Contudo, na maioria das vezes, essa inserção se faz de maneira precária, tornando desiguais as realidades de famílias de acordo com sua chefia (masculina ou feminina). Sendo assim, este estudo propôs a análise dos chefes de família da área de expansão portuária do $\mathrm{BGV}$, com o intuito de estabelecer relações entre o local de moradia e o de trabalho.

As mulheres da área pesquisada ainda estão sujeitas a velhos papéis da divisão sexual do trabalho feminino, não sendo inseridas em todos os espaços produtivos, o que as ceifa de possibilidades de melhoria na situação laboral e consequentemente da melhoria das condições da família a qual se responsabiliza. Destacamos a participação feminina na associação que ainda se apresenta tímida, pois dentre a hierarquia de funções, cabe à mulher a função de secretária, função típica feminina, sendo o mais alto posto de uma mulher dentro da agregação.

As habitações dos moradores(as) da área de remoção serão mantidas no bairro em uma área mais próxima ao centro da cidade. Porém ressaltamos que para as mulheres, a importância da relação ocupação/local de moradia é menor se comparada a dos homens, pois o tipo de atividade que exercem pode adaptar-se devido a informalidade e a desvalorização de atividades consideradas femininas. Se as moradias novas fossem em áreas distantes das atuais, as famílias de chefia masculina teriam maior prejuízo, pois são os homens que mais dependem do local de moradia para o trabalho, considerando a formalidade de suas ocupações.

Este artigo apresenta resultados relativos a apenas uma área sujeita a expansão portuária localizada no $\mathrm{BGV}$, porém permite aprofundar o entendimento da relação ocupação/local de moradia e fornece elementos para considerar sua importância no que se refere aos processos de remoção, dando subsídios para as outras cinco áreas.

\footnotetext{
${ }^{1}$ Refere-se a pesquisa 'Trabalho Feminino: o caso do processo de expansão nas áreas portuárias do porto de Rio Grande - RS' (Núcleo de Análises Urbanas NAU / FURG, 2010-2011)

2 Em 2007, o Núcleo de Análises Urbanas (NAU/FURG) deu início a realização de um levantamento socioeconômico com o objetivo de conhecer a situação das áreas passíveis de remoção.
} 
As áreas pesquisadas são: Barra Velha, Barra Nova, Bairro Getúlio Vargas, Santa Tereza, Mangueira e Barraquinhas; totalizando 1.923 moradias e 4.729 moradores(as).

3 Cada morador entrevistado corresponde a uma família.

${ }^{4}$ Segundo IBGE/POF, 1996, domicílio é o local de moradia estruturalmente separado e independente, constituído por um ou mais cômodos. O conceito de 'família' é mais abrangente e extrapola a unidade residencial (CARVALHO, 1998). Nesta pesquisa consideramos que o domicílio é a unidade residencial individual e a família é o grupo unido por laços de parentesco que reside no domicílio.

${ }^{5}$ Segundo IBGE (2004), entre 1950 e 2000, a taxa de fecundidade diminui de 6,21 para 2,38.

6 Segundo IBGE (2004, s.p) A partir de 1960, “as proporções de pessoas na condição de separadas não judicialmente se mantiveram estáveis em torno de $2,0 \%$, porém, em 1991, revelou-se um ligeiro aumento $(3,1 \%)$ na sua proporção. O conjunto das pessoas desquitadas ou separadas judicialmente e as divorciadas que mantinham proporções pouco expressivas, atingiram, em 2000, 2,7\% das pessoas de 15 anos ou mais de idade. Estes percentuais experimentaram aumentos paulatinos sobretudo a partir da década de 1980, em função da promulgação da Lei do Divórcio ocorrida em 26 de dezembro de 1977',

7 Ver BARROSO, 1978; CARVALHO, 1998; GALEAZZI, 2001; MACEDO, 2001; MENDES, 2002; DEMO, 2005; MONTALI, 2006.

8 Estão incluídas as ocupações: gestor de cooperativa, ajudante de armazenagem, eletricista, esmerilhador, lixador de peças de metal, pintor e montador de estruturas metálicas, encanador, soldador, auxiliar de operador de guincho, operador de trator de pátio, estivador/arrumador/portuário, operador de carga e descarga e serviços gerais, com um total de 78 casos.

${ }^{9}$ Um dos quatro casos da ocupação classificada como serviço de limpeza (não doméstico).

10 Entre diaristas, domésticas e lavadeiras no serviço doméstico foram 29 casos.

11 Destaca-se que entre os trabalhadores que sobrevivem da reciclagem, cinco são mulheres e dois são homens.

12 A secretária refere-se a uma assembleia de um sindicato vinculado aos trabalhadores no porto.

${ }^{13}$ Ver reportagem "Obras dos residenciais BGV I e II estão em desenvolvimento". Jornal Agora, 1819/12/2010, p. 4.

\section{Referências}

BARROSO, Cannon. Sozinhas ou mal acompanhadas. A situação das mulheres chefes de família. Anais do I Encontro de estudos Populacionais. Vol. 1, 1978, p. 457-486. Disponível em < http://www.abep.nepo.unicamp.br/...>. Acesso em maio de 2011.

BRITO, Fausto e BAENINGER, Rosana (Org.) Populações e políticas sociais no Brasil: os desafios da transição demográfica e das migrações internacionais. Brasília: Centro de Gestão e Estudos Estratégicos, 2008.

BUTLER, Judith. Problemas de gênero. feminismo e subversão da identidade. 2a . Ed. Rio de Janeiro: Civilização Brasileira, 2008.

CARVALHO, Luiza. A mulher trabalhadora na dinâmica da manutenção e da chefia domiciliar. Revista de estudos Feministas. v. 6, n. 1. Rio de Janeiro: IFCS/UFRJ, 1998.

DEMO, Pedro. Dureza: pobreza política de mulheres pobres. Campinas/SP: Autores Associados, 2005.

GALEAZZI, Irene Maria Sassi. Mulheres trabalhadoras a chefia da família e os condicionantes de gênero. Mulher e trabalho. v.1 Porto Alegre: FEE, 2001. Disponível em < http://www.fee.tche.br/sitefee/... . Acesso em maio de 2011.

GOLDANI, Ana. Maria. As famílias brasileiras: mudanças e perspectivas. Cadernos Pesquisa. São Paulo, n. 91, Nov, 1994.

HOFFMANN, Rodolfo; LEONE, Eugênia Troncoso. Participação da mulher no mercado de trabalho e desigualdade da renda domiciliar per capita no Brasil: 1981-2002. Nova Economia, Belo Horizonte, v. 14, n.2, maio-agosto de 2004. Disponível em $<$ http://www.face.ufmg.br/revista/index.php...> Acesso em 19 de maio de 2011.

INSTITUTO BRASILEIRO DE GEOGRAFIA E ESTATÍSTICA (IBGE). Notas Metodológicas. Disponível em <www.ibge.gov.br>. Acesso em abril de 2011. 
INSTITUTO BRASILEIRO DE GEOGRAFIA E ESTATÍSTICA (IBGE). Pesquisa de Orçamento Familiar (POF), 1996. Disponível em $<$ http://biblioteca.ibge.gov.br/>. Acesso em abril de 2011

INSTITUTO BRASILEIRO DE GEOGRAFIA E ESTATÍSTICA (IBGE). Censos 1872 e $\mathbf{1 8 9 0 .}$ Disponível em $<$ http://biblioteca.ibge.gov.br/>. Acesso em abril de 2011.

INSTITUTO BRASILEIRO DE GEOGRAFIA E ESTATÍSTICA (IBGE). Tendências Demográficas: uma análise dos resultados da amostra do censo demográfico 2000. Rio de Janeiro: IBGE, 2004.

LOPES, Cledir da C. A construção social do bairro Getúlio Vargas - Rio Grande/RS: processos e dinâmicas na formação de uma vila operária. Trabalho de Conclusão do Curso (Graduação em Geografia) Universidade Federal do Rio Grande. Rio Grande, 2008.

LOPES, Cristiane Maria Sbalqueiro. Direito do trabalho da mulher: da proteção à promoção. Cadernos Pagu (26), janeiro-junho de 2006: p.405430. Disponível em <http://www.ieg.ufsc.br/admin/...> Acesso em 19 de maio de 2011.

MACÊDO, Márcia dos Santos. Tecendo o fio e segurando as pontas: mulheres chefes de família em Salvador. In: BRUSCHINI, Cristina e PINTO, Celi Regina. (Org.) Tempos e lugares de gênero. São Paulo: FCC e Editora 34, 2001.

MARTINS, C. A. et al. RELATÓRIO BGV-NAU. Georeferenciamento do Bairro Getúlio Vargas: delimitação topográfica com implantação de marcos físicos no terreno e mensuração da área atingida pela expansão portuária, Rio Grande, FURG, 2008.

MENDES, Mary Alves. Mulheres chefes de família: a complexidade e ambiguidade da questão. In: XIII Encontro da Associação Brasileira de Estudos Populacionais/ABEP, 2002. Disponível em $<$ http://www.abep.nepo.unicamp.br/docs/... > Acesso em 19 de maio de 2011

MONTALI, Lilia. Família e Trabalho na Reestruturação Produtiva: Ausência de políticas de emprego e deterioração das condições de vida. Revista Brasileira de Ciências Sociais, v.15 n. 42. São Paulo, fev., 2000. Disponível em <http://www.scielo.br/...> Acesso em 19 de maio de 2011.
.Provedoras e co-provedoras: mulheres cônjuges e mulheres-chefes de família sob a precarização do trabalho e o desemprego. Revista Brasileira de Estudos Populacionais. v. 23, n. 2, juldez., 2006, p. 223-246.

SAFFIOTI, Heleieth. Quem tem medo dos esquemas patriarcais de pensamento? Dossiê Crítica Marxista. n. $\quad 2000$. Disponível em $<$ http://www.unicamp.br/cemarx/... . . Acesso em 19 de Abril de 2011.
Recebido em: 22 de novembro de 2011. Aceito em: 2 de fevereiro de 2012. 